\title{
Relação clínica entre hábitos de sucção, má oclusão, aleitamento e grau de informação prévia das mães
}

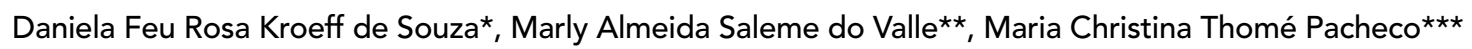

\section{Resumo}

Objetivo: este estudo avaliou a relação clínica entre a forma de aleitamento da criança, orientação prévia das mães sobre amamentação natural, instalação de hábitos de sucção não-nutritivos e a presença de más oclusões. Metodologia: foram examinadas 79 crianças (39 com hábitos de sucção e 40 sem hábitos de sucção), de ambos os gêneros, entre 2 e 5 anos, com a dentadura decídua completa e sem perda de tecido dentário interproximal, selecionadas de maneira randomizada, que participavam do Projeto de Bebês da Universidade Federal do Espírito Santo. Apenas um examinador (Kappa intra-examinador: 0,96) avaliou as características faciais e oclusais das crianças, no sentido ântero-posterior, transversal e vertical. As mães foram instruídas a responderem um questionário sobre o desenvolvimento da criança e o grau de orientação prévia que receberam sobre amamentação natural, hábitos, más oclusões e respiração bucal. Foram empregados os testes estatísticos qui-quadrado, teste exato de Fischer, t de Student e Odds Ratio. Resultados: os resultados mostraram que: 1) existe uma relação estatisticamente significante entre o prolongamento do aleitamento materno e a redução da instalação de hábitos de sucção $(\mathrm{p}<0,01)$; 2) a orientação prévia das mães sobre amamentação natural resultou num prolongamento no tempo de aleitamento natural, para crianças com e sem hábitos $(\mathrm{p}<0,01)$; 3$)$ crianças com hábitos tiveram maior risco relativo de desenvolver más oclusões no sentido vertical (OR: 12,8), transversal (OR: 4,25) e alteração ântero-posterior na relação dos caninos $(\mathrm{p}<0,01)$. A alteração da relação ântero-posterior dos segundos molares decíduos não mostrou diferença estatisticamente significante (p:0,07). Conclusão: os resultados sugerem que o grau de informação das mães e o prolongamento do período de aleitamento natural estão diretamente relacionados com a menor incidência de más oclusões nessa fase do desenvolvimento da criança.

Palavras-chave: Hábitos de sucção. Má oclusão. Amamentação.

* Cirurgiã- Dentista. Aluna da especialização em Ortodontia da Universidade do Estado do Rio de Janeiro.

** Mestre em Odontopediatria pela UFRJ e professora adjunta da disciplina de Odontopediatria da Universidade Federal do Espírito Santo.

*** Mestre e Doutora em Ortodontia pela UFRJ e professora adjunta da disciplina de Ortodontia da Universidade Federal do Espírito Santo. 


\section{INTRODUÇÃO}

De acordo com Moyers ${ }^{10}$, após a complementação da dentadura decídua, a criança não deve mais apresentar hábitos de sucção, uma vez que, nessa idade, o instinto de sucção deve ser substituído pelo de morder e pegar. O prolongamento da fase oral não é fisiológico e hábitos perpetuados além dessa fase tornam-se deletérios. O hábito de sucção deletério contribui como fator etiológico em potencial na deterioração da oclusão $\mathrm{o}^{13,16} \mathrm{e}$ pode transformar-se em hábito nocivo, de acordo com a freqüência, intensidade e duração do movimento, pré-disposição individual, idade e, também, de acordo com as condições de nutrição e, conseqüentemente, de saúde do indivíduo ${ }^{8,10,12}$.

O objetivo desse estudo foi avaliar a existência de relação causal entre a presença de hábitos de sucção não-nutritivos, tipo de aleitamento, orientação prévia das mães e a instalação de más oclusões nos sentidos ântero-posterior, vertical e transversal em crianças na dentadura decídua.

\section{MATERIAL E MÉTODOS}

A amostra foi constituída de 79 crianças, entre dois e cinco anos de idade, de ambos os gêneros, que freqüentavam o Projeto de Bebês, do Departamento de Clínica Odontológica da Universidade Federal do Espírito Santo, em Vitória. Elas obedeceram aos seguintes critérios de inclusão e exclusão:

- Grupo Caso: como critérios de inclusão, a presença de um ou mais hábitos de sucção não-nutritiva (sendo considerados os hábitos de chupeta, sucção digital e sucção de lábio) e da dentadura decídua completa. Como critérios de exclusão, o abandono do hábito por um período superior a seis meses, a presença de dentes permanentes, de lesões de cárie ou restaurações inadequadas, que comprometessem o perímetro do arco e assimetrias significantes. Estas crianças também não poderiam estar usando qualquer tipo de aparelho ortodôntico e nem terem sido submetidas a esse tratamento no passado.

- Grupo Controle: como critério de inclusão, a ausência de qualquer hábito de sucção não-nutritiva e a presença da dentadura completa. Como critérios de exclusão, a presença de dentes permanentes, de lesões de cárie ou restaurações inadequadas que comprometessem o perímetro do arco e assimetrias significantes. Estas crianças também não poderiam estar usando qualquer tipo de aparelho ortodôntico e nem terem sido submetidas a esse tratamento no passado. A presença de má oclusão não foi considerada um critério de exclusão para crianças sem hábitos.

Com a aplicação dos critérios de exclusão, houve uma perda de $28,1 \%$ da amostra inicial das crianças do grupo Caso. Portanto, o grupo Caso foi constituído de 39 crianças que possuíam hábitos de sucção.

O grupo Controle foi formado por 40 crianças sem hábitos de sucção, selecionadas por meio de uma tabela de números aleatórios, dentre todas as que participavam do Projeto de Bebês e não tinham hábitos.

As mães ou responsáveis por estas crianças responderam um questionário com perguntas acerca da forma de aleitamento recebida pela criança, sendo definido como: aleitamento natural exclusivo até os seis meses, natural exclusivo até três meses, aleitamento misto antes dos três meses ou artificial desde o nascimento. Foram também questionadas se receberam informação sobre amamentação, hábitos de sucção não-nutritiva, más oclusões e respiração bucal e onde foram orientadas. O responsável assinou um consentimento livre-esclarecido (aprovado no Comitê de Ética em pesquisa do CBMUFES), permitindo a participação de seu filho ou da criança pela qual era responsável na pesquisa, assim como a realização do exame clínico e o uso do material para fins didáticos/científicos.

Os exames foram realizados por um examinador, que inicialmente verificou a relação dos lábios superior e inferior em repouso (se apresentava ou não selamento labial). No exame clínico intrabucal foram avaliadas as variações nos sentidos ântero-posterior (relação terminal dos segundos 
molares decíduos e relação dos caninos decíduos); transversal (relação maxilo-mandibular, sendo consideradas atrésicas as maxilas com mordida cruzada posterior uni ou bilateral ou relação de topo latero-lateral) e vertical (relação com o Plano Oclusal), com o auxílio de régua milimetrada endodôntica, compasso de pontas secas, espelho clínico e luvas de procedimento. Os dados foram anotados em uma ficha clínica individual.

O único examinador envolvido neste estudo foi calibrado por um grupo de professores da universidade, com ampla experiência no diagnóstico da oclusão dentária na dentadura decídua. Para determinar se havia risco de erro intra-examinador, após a coleta de dados de quinze pacientes, o mesmo grupo foi reavaliado após o período de dez dias. O valor de Kappa para os indicadores das más oclusões avaliadas foi 0,96 , sendo considerado adequado para a realização da pesquisa, de acordo com Eklund et al. ${ }^{4}$

\section{RESULTADOS E DISCUSSÃO}

Os resultados obtidos para os grupos Caso e Controle e a análise estatística realizada para avaliar as diferenças entre os grupos encontram-se nas tabelas de 1 a 4 e nos gráficos de 1 a 4 . Os testes estatísticos empregados foram o qui-quadrado, teste exato de Fischer, teste t de Student e Odds Ratio.

\section{Amamentação e orientação}

As mães das crianças do grupo Controle receberam estatisticamente mais orientação prévia sobre amamentação, hábitos, má oclusão e respiração bucal do que as mães das crianças do grupo Caso (Tab. 2). A orientação sobre amamentação foi a mais recebida pelas mães dos dois grupos e foi estatisticamente superior, no grupo Controle. O local onde essas mães mais indicaram terem sido orientadas foi o Hospital Maternidade - Hospital Universitário Cassiano Antônio Moraes (HUCAM) (Tab. 2).

O tipo de amamentação estatisticamente superior no grupo de crianças com hábito foi o artificial desde o nascimento e o tipo menos freqüente foi a amamentação natural exclusiva até seis meses. No grupo de crianças sem hábitos, o aleitamento natural exclusivo até os seis meses foi estatisticamente superior e o tipo de aleitamento menos freqüente foi o artificial desde o nascimento (Tab. 1). Crianças sem hábitos foram amamentadas naturalmente por um período de tempo maior (três e seis meses) do que as crianças com hábitos $(\mathrm{p}<0,01)$. De acordo com o teste $\mathrm{OR}=6,6$, crianças que nunca mamaram no peito ou que tiveram aleitamento misto antes dos três meses têm aproximadamente sete vezes mais chance de desenvolverem hábitos de sucção do que crianças que tiveram amamentação natural por três ou seis meses.

Braghini et al. ${ }^{2}$, Faria et al. ${ }^{5}$, Oliveira ${ }^{11}$ e SerraNegra et al. ${ }^{14}$ também encontraram relação estatisticamente significante entre a presença de hábitos em crianças com amamentação artificial desde o nascimento. Os achados de Serra-Negra et al. ${ }^{14}$ mostraram ainda que as crianças que nunca receberam aleitamento materno ou receberam por até um mês apresentam risco de desenvolver hábitos de sucção aproximadamente sete vezes superior do que aquelas que receberam aleitamento materno por seis meses ou mais.

No presente estudo, observa-se que, das crianças que apresentaram sucção de chupeta, 88,23\% receberam aleitamento artificial desde o nascimento; $78,57 \%$ receberam aleitamento misto antes dos três meses, $65 \%$ receberam três meses de amamentação natural e 50\% tiveram seis meses de amamentação natural, sendo que essa redução no período de aleitamento materno em crianças com hábito de sucção de chupeta apresentou relação estatisticamente significativa $(p<0,01)$. Na pesquisa de Oliveira ${ }^{11}$ foram obtidos dados similares: $90 \%$ das crianças que receberam aleitamento artificial apresentaram sucção de chupeta, e a tendência de decréscimo no uso da chupeta em relação ao aumento no período de aleitamento natural também apresentou resultados estatisticamente significantes.

No presente estudo, as mães que receberam 
orientação sobre a importância da amamentação no grupo controle amamentaram a criança no peito por um periodo estatisticamente superior do que as mães que também eram do grupo Controle, mas que não receberam orientação (Tab. 2). O mesmo ocorreu no grupo Caso, onde houve um acréscimo de $50 \%$ de aleitamento natural por três e seis meses, quando as mães desse grupo receberam orientação sobre amamentação (Tab. 2). Esses dados corroboram as conclusões de Venâncio et al. ${ }^{17}$, que sugeriram que o baixo percentual de amamentação materna exclusiva por seis meses ocorreu devido à orientação deficiente dessas mães. Os pesquisadores notaram que a maioria dos bebês que ingeriam apenas leite materno havia nascido em hospitais "Amigos da Criança". Uma vez que o local mais apontado para a orientação das mães no presente trabalho foi o Hospital Maternidade (HUCAM), o esforço para a adesão desse hospital no projeto "Amigos da Criança" é importante para estimular o aleitamento materno, contribuindo para melhorar a saúde e a qualidade de vida dessas crianças.

\section{Hábitos}

O início do hábito de sucção no grupo Caso ocorreu ao nascimento em 49\% das crianças; durante o primeiro mês de vida em $33 \%$; com aproximadamente três meses de vida em $10 \%$ e com aproximadamente seis meses em $8 \%$ das crianças (Gráf. 1). Ao relacionar a orientação das mães e o início do hábito de chupeta, constatou-se que aquelas que foram orientadas ofertaram a chupeta estatisticamente mais tarde aos seus filhos (Tab. 3).

O tipo prevalente de hábito foi o da chupeta $(77,9 \%)$, com diferença estatisticamente significativa em relação aos demais hábitos apresentados no grupo Caso $(\mathrm{p}<0,01)$ (Gráf. 2). Faria et al. ${ }^{5}$, Serra-Negra et al. ${ }^{14}$ e Silva Filho et al. ${ }^{16}$ também constataram prevalência significativa do hábito da chupeta $(75,1 \%, 79 \%$ e $60 \%$ das crianças estudadas, respectivamente). No presente estudo não foi encontrado nenhum caso de sucção de lábio e a sucção digital do polegar foi encontrada em
$14,4 \%$ dos casos e do indicador em 3,6\%. Houve associação de hábitos de sucção digital e uso de chupeta em $4,1 \%$ das crianças, o que gera um total de $82 \%$ de sucção de chupeta e $22,1 \%$ de sucção digital, quando se considera a associação dos hábitos. Serra-Negra et al. ${ }^{14}$ observaram que a sucção de dedos ocorreu em 10\% das crianças, Faria et al. ${ }^{5}$ em $11 \%$ das crianças e Silva Filho et al. ${ }^{16}$ em $10 \%$ das crianças. A incidência da sucção digital no presente estudo foi superior aos levantamentos prévios, provavelmente devido à escolha da amostra do grupo Caso ser 100\% composta de crianças com um ou mais hábitos de sucção não nutritiva, considerando hábitos de chupeta, lábio ou dedo.

\section{O desenvolvimento das más oclusões}

A correlação entre presença de hábitos e desenvolvimento de más oclusões mostrou-se estatisticamente relevante (Tab. 1). O teste OR indicou que crianças com hábitos de sucção possuem, aproximadamente, doze vezes mais chance de desenvolverem más oclusões do que crianças que não tenham hábitos de sucção.

Köhlerne e Holst ${ }^{9}$ observaram que as más oclusões foram mais freqüentes entre as crianças portadoras de hábitos de sucção, com uma prevalência de $61,6 \%$ e significância estatística. Do mesmo modo, Ferreira et al. ${ }^{7}$ observaram prevalência de $76,80 \%$ e significância estatística e Silva Filho et al. ${ }^{16}$ encontraram uma prevalência de $73,34 \%$. A presença de crianças com hábitos de sucção que não apresentavam más oclusões pode ser explicada pela necessidade de haver duração (principalmente) e intensidade prolongadas do hábito, associadas ao padrão muscular e à predisposição genética do paciente, representada de forma principal por seu padrão de crescimento e desenvolvimento craniofacial ${ }^{10,12}$.

\section{Relação ântero-posterior de molares decíduos}

A relação ântero-posterior foi analisada através do plano terminal dos segundos molares decíduos. No grupo de crianças que não possuíam hábitos, $67,5 \%$ apresentaram plano reto e $27,5 \%$ apresen- 
Tabela 1 - Freqüências absoluta e relativa das características dos grupos caso e controle.

\begin{tabular}{|c|c|c|c|c|c|c|}
\hline \multirow{2}{*}{ características } & \multicolumn{2}{|c|}{ grupo caso $(n=39)$} & \multicolumn{2}{|c|}{ grupo controle $(n=40)$} & \multirow{2}{*}{ p valor } & \multirow{2}{*}{ OR } \\
\hline & $n^{\circ}$ & $\%$ & $n^{\circ}$ & $\%$ & & \\
\hline \multicolumn{7}{|l|}{ gênero } \\
\hline feminino & 21 & $52,50 \%$ & 26 & $65 \%$ & \multirow{2}{*}{$\mathrm{p}=0,07$ n.s. } & \multirow{2}{*}{-} \\
\hline masculino & 18 & $47,50 \%$ & 14 & $35 \%$ & & \\
\hline \multicolumn{7}{|l|}{ forma de aleitamento } \\
\hline artificial desde o nascimento & 17 & $43,60 \%$ & 3 & $7,50 \%$ & \multirow{4}{*}{$\mathrm{p}<0,01$} & \multirow{4}{*}{-} \\
\hline misto antes dos três meses & 14 & $35,90 \%$ & 4 & $10,25 \%$ & & \\
\hline natural exclusivo até três meses & 4 & $10,20 \%$ & 8 & $20,50 \%$ & & \\
\hline natural exclusivo até seis meses & 4 & $10,20 \%$ & 25 & $62,50 \%$ & & \\
\hline presença de má oclusão & 29 & $74,40 \%$ & 8 & $20 \%$ & $p<0,01$ & 11,6 \\
\hline \multicolumn{7}{|l|}{ perfil } \\
\hline reto & 25 & $64,10 \%$ & 31 & $77,50 \%$ & \multirow{3}{*}{$p<0,01$} & \multirow{3}{*}{-} \\
\hline convexo & 14 & $35,90 \%$ & 8 & $20 \%$ & & \\
\hline côncavo & - & - & 1 & $2,50 \%$ & & \\
\hline \multicolumn{7}{|l|}{ relação ântero-posterior de molares decíduos } \\
\hline normal (plano reto e degrau mesial) & 32 & $82,10 \%$ & 38 & $95 \%$ & \multirow{2}{*}{$\mathrm{p}=0,07$ n.s. } & \multirow{2}{*}{-} \\
\hline degrau distal & 7 & $17,90 \%$ & 2 & $5 \%$ & & \\
\hline \multicolumn{7}{|l|}{ relação ântero-posterior de caninos decíduos } \\
\hline normal (degrau mesial) & 25 & $64,10 \%$ & 35 & $87,50 \%$ & \multirow{2}{*}{$p<0,05$} & \multirow{2}{*}{-} \\
\hline alterado (plano reto e degrau distal) & 14 & $35,90 \%$ & 5 & $12,50 \%$ & & \\
\hline \multicolumn{7}{|l|}{ relação transversal } \\
\hline normal & 29 & $74,40 \%$ & 37 & $92,50 \%$ & \multirow{2}{*}{$p<0,05$} & \multirow{2}{*}{4,25} \\
\hline atrésica (cruzada uni ou bilateral) & 10 & $25,60 \%$ & 3 & $7,50 \%$ & & \\
\hline cruzada unilateral & 4 & $40 \%$ & 0 & 0 & $p<0,01$ & - \\
\hline \multicolumn{7}{|l|}{ forma do arco } \\
\hline normal & 22 & $56,40 \%$ & 38 & $95 \%$ & \multirow{2}{*}{$p<0,01$} & \multirow{2}{*}{14,7} \\
\hline V & 17 & $43,60 \%$ & 2 & $5 \%$ & & \\
\hline \multicolumn{7}{|l|}{ relação vertical } \\
\hline normal & 11 & $28,20 \%$ & 29 & $72,50 \%$ & & \\
\hline relação de topo & 8 & $20,50 \%$ & 7 & $17,50 \%$ & & \\
\hline sobremordida profunda & 2 & $5,10 \%$ & 1 & $2,50 \%$ & $\mathrm{p}<0,01$ & 10,8 \\
\hline trespasse invertido & 1 & $2,60 \%$ & 0 & 0 & & \\
\hline mordida aberta anterior & 17 & $43,60 \%$ & 3 & $7,50 \%$ & & \\
\hline média da amplitude -MAA- (mm) & $2,16 \mathrm{~mm}$ & - & $0,9 \mathrm{~mm}$ & - & $\mathrm{p}<0,05$ & - \\
\hline selamento labial & & & & & & \\
\hline $\operatorname{sim}$ & 24 & $61,50 \%$ & 38 & $95 \%$ & $n=001$ & 110 \\
\hline não & 15 & $38,50 \%$ & 2 & $5 \%$ & $p<0,001$ & 11,9 \\
\hline
\end{tabular}

n.s.= não significativo.

$\mathrm{P}<0,01=$ significativo ao nível de $99 \%$ de probabilidade; $\mathrm{P}<0,05=$ significativo ao nível de $95 \%$ de probabilidade. 
Tabela 2 - Freqüências absoluta e relativa da orientação das mães dos grupos Caso e Controle e análise estatística.

\begin{tabular}{|c|c|c|c|c|c|}
\hline \multirow[t]{2}{*}{ orientação } & \multicolumn{2}{|c|}{$\begin{array}{l}\text { grupo caso } \\
\text { n: } 39\end{array}$} & \multicolumn{2}{|c|}{$\begin{array}{c}\text { grupo } \\
\text { controle } \\
\text { n: } 40\end{array}$} & \multirow[t]{2}{*}{ p valor } \\
\hline & $n^{\circ}$ & $\%$ & $n^{\circ}$ & $\%$ & \\
\hline \multicolumn{6}{|c|}{$\begin{array}{l}\text { mãe recebeu orienta- } \\
\text { ção prévia }\end{array}$} \\
\hline $\operatorname{sim}$ & 16 & $41 \%$ & 26 & $65 \%$ & \multirow{2}{*}{$p<0,05$} \\
\hline não & 23 & $59 \%$ & 14 & $35 \%$ & \\
\hline
\end{tabular}

\begin{tabular}{|c|c|c|c|c|c|}
\hline $\begin{array}{l}\text { tipo de orientação } \\
\text { recebida }\end{array}$ & & & & & \\
\hline amamentação & 16 & $41 \%$ & 26 & $65 \%$ & $\mathrm{p}<0,05$ \\
\hline respiração bucal & 12 & $30,80 \%$ & 15 & $38,50 \%$ & n.s. \\
\hline má oclusão & 7 & $17,90 \%$ & 9 & $22,50 \%$ & n.s. \\
\hline hábitos de sucção & 11 & $28,20 \%$ & 18 & $45 \%$ & n.s. \\
\hline \multicolumn{6}{|l|}{ local onde foi orientada } \\
\hline projeto bebê & 5 & $26,30 \%$ & 10 & $38,50 \%$ & n.s. \\
\hline hospital maternidade & 10 & $52,60 \%$ & 16 & $61,50 \%$ & n.s. \\
\hline posto de saúde & 1 & $5,30 \%$ & 0 & 0 & - \\
\hline \multicolumn{6}{|l|}{$\begin{array}{l}\text { tipo de aleitamento } \\
\text { proporcionado pelas } \\
\text { mães orientadas }\end{array}$} \\
\hline $\begin{array}{l}\text { total que recebeu } \\
\text { orientação }\end{array}$ & 16 & $41 \%$ & 26 & $65 \%$ & $\mathrm{p}<0,05$ \\
\hline $\begin{array}{l}\text { artificial desde o nas- } \\
\text { cimento }\end{array}$ & 2 & $12,50 \%$ & 1 & $3,80 \%$ & \multirow{4}{*}{$p<0,01$} \\
\hline $\begin{array}{c}\text { misto antes dos três } \\
\text { meses }\end{array}$ & 6 & $37,50 \%$ & 1 & $3,80 \%$ & \\
\hline $\begin{array}{l}\text { natural exclusivo até } \\
\text { três meses }\end{array}$ & 4 & $25 \%$ & 8 & $30,80 \%$ & \\
\hline $\begin{array}{l}\text { natural exclusivo até } \\
\text { seis meses }\end{array}$ & 4 & $25 \%$ & 16 & $61,60 \%$ & \\
\hline \multicolumn{6}{|l|}{$\begin{array}{l}\text { tipo de aleitamento } \\
\text { proporcionado pelas } \\
\text { mães não orientadas }\end{array}$} \\
\hline $\begin{array}{l}\text { total que não recebeu } \\
\text { orientação }\end{array}$ & 23 & $59 \%$ & 14 & $35 \%$ & $\mathrm{p}<0,05$ \\
\hline $\begin{array}{l}\text { artificial desde o nas- } \\
\text { cimento }\end{array}$ & 15 & $65,20 \%$ & 2 & $14,30 \%$ & \multirow{4}{*}{$\mathrm{p}<0,05$} \\
\hline $\begin{array}{c}\text { misto antes dos três } \\
\text { meses }\end{array}$ & 8 & $34,80 \%$ & 3 & $21,42 \%$ & \\
\hline $\begin{array}{l}\text { natural exclusivo até } \\
\text { três meses }\end{array}$ & 0 & 0 & 0 & 0 & \\
\hline $\begin{array}{l}\text { natural exclusivo até } \\
\text { seis meses }\end{array}$ & 0 & 0 & 9 & $64,28 \%$ & \\
\hline
\end{tabular}

taram degrau mesial, resultando em 95\% de relação normal dos molares na dentadura decídua. Já o degrau distal foi encontrado em $5 \%$ das crianças. Resultados similares foram encontrados por Bau$\mathrm{me}^{1}$, Oliveira ${ }^{11}$ e Shimizu et al. ${ }^{15}$ No presente estudo, essa relação no grupo de crianças com hábitos mostrou um percentual aumentado de degrau distal, igual a 17,9\% que, todavia, não apresentou significância estatística em relação ao grupo Controle (Tab. 1), corroborando os achados de Silva Filho et al. ${ }^{16}$ Dentre as crianças que apresentavam degrau distal de molar na dentição decídua, $55,5 \%$ usavam chupeta e $22,2 \%$ chupavam o dedo. Do mesmo modo, Faria et al. ${ }^{5}$ encontraram a sucção de chupeta e a sucção digital como fatores de risco para esta condição, apesar de também não ter havido significância estatística.

\section{Relação ântero-posterior de caninos decíduos}

No presente estudo, o deslocamento dos caninos superiores, levando a uma relação de topo ou degrau distal, mostrou diferença estatisticamente significante entre o grupo Controle e o grupo Caso (Tab. 1), demonstrando que o deslocamento dos caninos superiores para mesial é mais freqüente que o dos molares superiores em crianças com hábitos. É importante salientar que em todos os casos em que houve o deslocamento mesial dos molares superiores, os caninos superiores também estavam deslocados, todavia, em algumas situações, apenas os caninos estavam deslocados para mesial e os molares apresentavam posicionamento normal. Os valores percentuais encontrados para a relação dos caninos no grupo Controle corroboram os achados de Faria et al. ${ }^{5}$

\section{Relação transversal}

A presença de relação transversal atrésica foi estatisticamente maior no grupo de crianças com hábitos $(25,6 \%)$, em relação às crianças sem hábitos $(7,5 \%)$. Foi observado que crianças que possuem hábitos de sucção têm aproximadamente quatro vezes mais chance de apresentarem 




GRÁFICO 1 - Idade em que houve o início do hábito de sucção, segundo as mães.

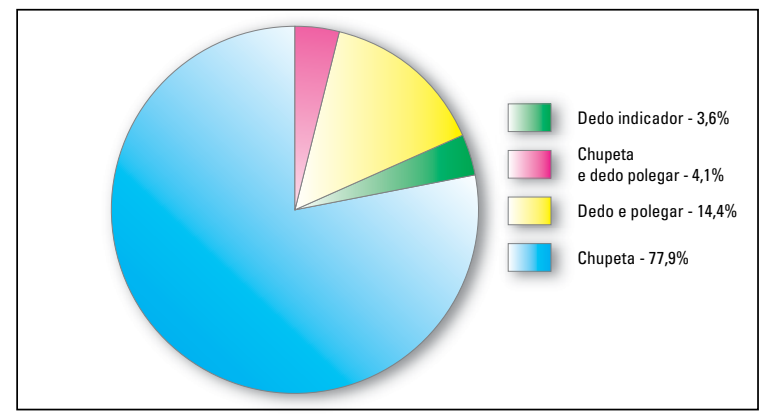

GRÁFICO 2 - Tipo prevalente de hábito no grupo caso.

0 teste qui-quadrado mostrou diferença estatisticamente significante entre os grupos $\left(x^{2}=2,75 ; p<0,01\right)$.

as maxilas atrésicas do que crianças que não tenham hábitos (Tab. 1). Os resultados corroboram os achados de Serra-Negra et al. ${ }^{14}$, que também demonstraram haver relação estatisticamente significante entre a presença de hábitos e o desenvolvimento da mordida cruzada posterior, e uma chance aproximadamente quatro vezes maior de crianças com hábitos desenvolverem mordida cruzada posterior. Silva Filho et al. ${ }^{16}$ relataram a presença de aproximadamente 30\% de mordidas cruzadas nas crianças com hábitos que avaliaram e Ferreira e Toledo ${ }^{7}$ encontraram esta má oclusão em $15,45 \%$ das crianças com hábitos. Oliveira ${ }^{11}$ encontrou $14,3 \%$ de mordidas cruzadas em crianças que usam ou usaram chupeta e $8,4 \%$ nas que nunca usaram. Este autor não encontrou relação significante entre os hábitos de sucção e a presença de mordida cruzada posterior.

No presente estudo, a alteração da forma do arco maxilar de semicircular para a forma em $\mathrm{V}$ foi su-
Tabela 3 - Idade em que a chupeta foi ofertada à criança versus orientação das mães.

\begin{tabular}{ccccc}
\hline $\begin{array}{c}\text { tempo após nasci- } \\
\text { mento }\end{array}$ & recebeu orientação & \multicolumn{2}{c}{$\begin{array}{c}\text { não recebeu orien- } \\
\text { tação }\end{array}$} \\
\hline & $\mathbf{n}^{\mathbf{0}}$ & $\%$ & $\mathbf{n}^{\mathbf{0}}$ & $\%$ \\
\cline { 2 - 5 } ao nascer e $1^{\circ}$ mês & 6 & 60 & 20 & 100 \\
até $06^{\circ}$ mês & 4 & 40 & 0 & 0 \\
Total & 10 & 100 & 20 & 100 \\
\hline
\end{tabular}

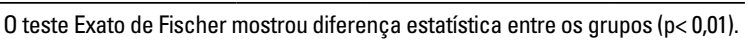

Tabela 4 - Relação entre mordida aberta anterior e selamento labial.

\begin{tabular}{|c|c|c|c|c|c|}
\hline \multirow[t]{2}{*}{ selamento } & \multicolumn{2}{|c|}{$\begin{array}{l}\text { com mordida } \\
\text { aberta }\end{array}$} & \multicolumn{2}{|c|}{$\begin{array}{l}\text { sem mordida } \\
\text { aberta }\end{array}$} & \multirow{2}{*}{$\frac{p \text { valor }}{x^{2}}$} \\
\hline & $n^{\circ}$ & $\%$ & $n^{\circ}$ & $\%$ & \\
\hline \multicolumn{6}{|c|}{ grupo caso e grupo controle n: 79} \\
\hline com selamento & 5 & $25 \%$ & 57 & $96,60 \%$ & \multirow{2}{*}{$\mathrm{p}<0,01$} \\
\hline sem selamento & 15 & $75 \%$ & 2 & $3,40 \%$ & \\
\hline \multicolumn{6}{|c|}{ grupo caso $n: 39$} \\
\hline com selamento & 3 & $17,60 \%$ & 21 & $95,50 \%$ & \multirow{2}{*}{$\mathrm{p}<0,01$} \\
\hline sem selamento & 14 & $82,40 \%$ & 1 & $4,50 \%$ & \\
\hline \multicolumn{6}{|c|}{ grupo controle n: 40} \\
\hline com selamento & 1 & $33,30 \%$ & 37 & $100 \%$ & \multirow{2}{*}{$\mathrm{p}<0,01$} \\
\hline sem selamento & 2 & $66,70 \%$ & 0 & 0 & \\
\hline
\end{tabular}

0 teste qui-quadrado mostrou diferença estatística entre os grupos $\left(x^{2}=45,3\right.$; 24,52 e 15,27 respectivamente)

$\mathrm{p}<0,01=$ significativo ao nível de $99 \%$ de probabilidade;

$p<0,05=$ significativo ao nível de $95 \%$ de probabilidade .

perior no grupo Caso $(43,6 \%)$ em relação ao grupo Controle (5\%); apresentou relação significativa e risco relativo aproximadamente quinze vezes superior de crianças com hábitos apresentarem arco em V (Tab. 1). Em todos os casos de mordida cruzada ou relação de topo, o arco superior estava em $\mathrm{V}$, contudo, o arco em V estava presente também em outras alterações, como a mordida aberta anterior, em que não havia mordida cruzada ou relação de topo. Esses valores corroboram os de Braghini et al. ${ }^{2}$

\section{Relação vertical}

A mordida aberta anterior foi a alteração oclusal mais observada entre as crianças que possuem 


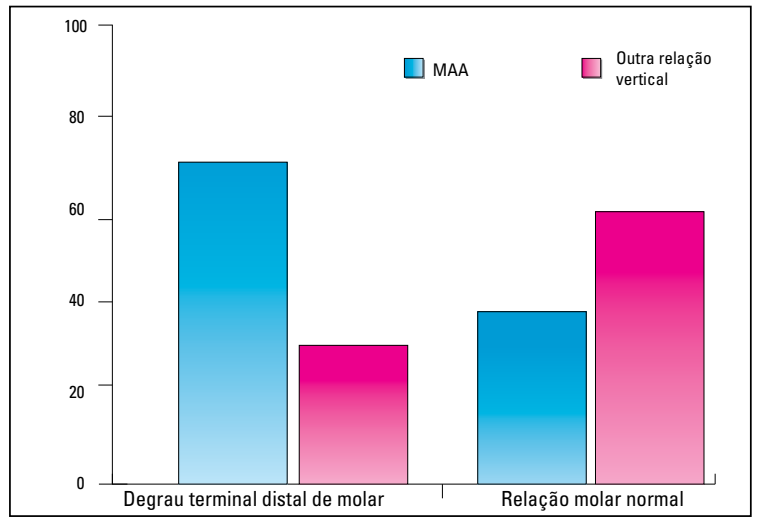

GRÁFICO 3 - Relação entre degrau distal de molares decíduos e mordida aberta anterior (MAA).

0 teste qui-quadrado não mostrou diferença estatística entre os grupos $\left(x^{2}=2,69 ; p=0,10\right)$

hábitos de sucção deletérios, corroborando os resultados de Serra-Negra et al. ${ }^{14}$, Zuanon et al. ${ }^{18} \mathrm{e}$ Silva Filho et al. ${ }^{16}$ No presente estudo, a mordida aberta anterior desenvolveu-se em $43,7 \%$ de crianças com hábitos; a correlação entre a presença de hábitos e o desenvolvimento de mordida aberta anterior foi estatisticamente significante; e crianças com hábitos de sucção tiveram aproximadamente onze vezes mais chance de desenvolver mordida aberta anterior do que crianças sem hábitos (Tab. 1). Do mesmo modo, Serra-Negra et al. ${ }^{14}$ encontraram um risco relativo aproximadamente quatorze vezes maior de crianças com hábitos desenvolverem mordida aberta anterior.

No presente estudo, a comparação da amplitude da mordida aberta anterior apresentada no grupo Caso $(2,16 \mathrm{~mm})$ com a apresentada no grupo Controle $(0,9 \mathrm{~mm})$ indicou que, além de mais freqüente, a mordida aberta anterior de pacientes com hábitos foi também de maior magnitude (Tab. 1).

A ausência de selamento labial foi estatisticamente superior nas crianças com hábitos $(39,5 \%)$ do que nas crianças sem hábitos (5\%), de modo que crianças com hábitos têm aproximadamente doze vezes mais chance de não terem selamento labial do que crianças que não tenham hábitos (Tab.1). A relação entre mordida aberta anterior e ausência de selamento labial nos dois grupos

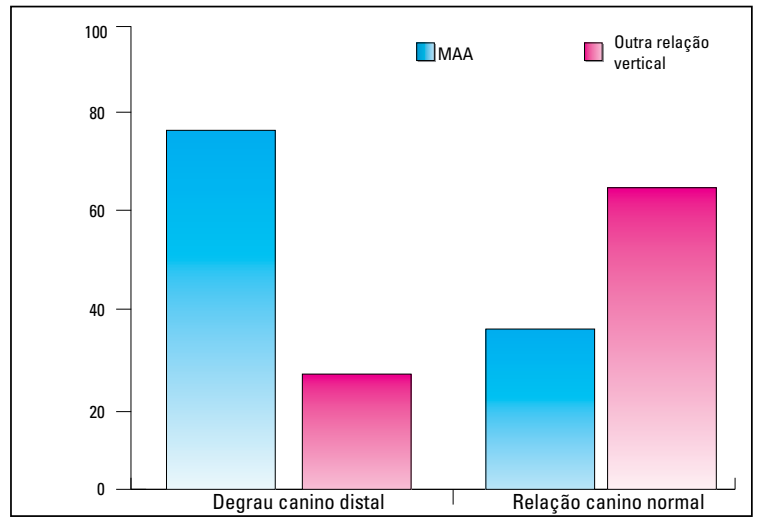

GRÁFICO 4 - Relação entre degrau distal de caninos e mordida aberta anterior (MAA).

0 teste qui-quadrado mostrou diferença estatística entre os grupos $\left(x^{2}=4,04\right.$; $\mathrm{p}<0,05)$.

(com e sem hábitos) apresentou relação estatisticamente significante (Tab. 4). Ao analisar essas alterações isoladamente no grupo Caso e no grupo Controle constatou-se que também houve significância estatística (Tab. 4). Também nos estudos de Oliveira ${ }^{11}, 97,3 \%$ dos pacientes que apresentaram mordida aberta anterior não apresentaram selamento labial, havendo relação estatisticamente significante. A relação entre degrau distal de molar e mordida aberta anterior (Gráf. 3), embora tenha apresentado uma relação percentual importante $(71,4 \%$ com mordida aberta anterior), não mostrou relação estatisticamente significante $(p=0,10)$. Já a relação de degrau distal nos caninos apareceu em 75\% das crianças que apresentavam mordida aberta anterior e foi estatisticamente significante $(\mathrm{p}<0,05)$, demonstrando que o deslocamento do canino para mesial está diretamente relacionado com o desenvolvimento da mordida aberta anterior (Gráf. 4).

\section{CONCLUSÕES}

Baseado nos resultados obtidos, é possível concluir para a população estudada que:

- Houve correlação significativa entre o tempo de aleitamento materno e a presença de hábitos, e quanto mais prolongado o período do aleitamento natural, menor foi a chance de uma criança desen- 
volver hábito de sucção deletério.

- A orientação das mães quanto à importância do aleitamento natural resultou num prolongamento do período de aleitamento materno exclusivo e num retardo na época de oferta da chupeta.

- O local mais importante para a orientação das mães foi o hospital maternidade. No intuito de alongar o período de amamentação natural, reduzindo o risco de instalação de hábitos e conseqüentemente más oclusões, um esforço deve ser feito para que os hospitais maternidade tornem-se "Hospitais Amigos da Criança"18.

- O tipo prevalente de hábito de sucção deletério foi o uso prolongado da chupeta.

- As crianças que possuíam hábitos de sucção deletérios tiveram mais chances de desenvolverem más oclusões que as que não possuíam hábitos.

- Na presença de hábitos deletérios houve um deslocamento do canino superior para uma posição mais mesial, todavia, esse deslocamento anterior é visto em menor quantidade para os molares.

- As crianças que possuíam hábitos de sucção tiveram aproximadamente doze vezes mais chance de não ter selamento labial; quinze vezes mais chance de ter a arcada em V; quatro vezes mais chance de ter atresia maxilar e onze vezes mais chance de desenvolverem mordida aberta anterior.

- As crianças com mordida aberta anterior foram mais propensas a apresentarem ausência de selamento labial e os caninos superiores deslocados para mesial.

- O grau de informação das mães sobre aleitamento materno está diretamente relacionado com a menor incidência de más oclusões nas crianças estudadas.

\title{
Clinical relationship among suction oral habits, malocclusion, infant feeding and mother's previous knowledge
}

\begin{abstract}
Aim: the proposal of this study was to associate infant feeding methods, mother's previous knowledge about breast-feeding, installation of oral habits and presence of malocclusions. Methods: 79 children (39 with suction habits and 40 without habits), both genres, from ages between 2 and 5 years old, with complete health deciduous dentition were randomizedly selected from the ones attended at Baby's Clinic, in Federal University of Espírito Santo. Only one examiner (Kappa intra-examiner $=0.96$ ) evaluated facial characteristics and the occlusion at transversal, antero-posterior and vertical relation. Each mother was oriented to answer a questionnaire concerning child's development and the degree of information she had received about breast-feeding, habits, malocclusion and oral breathing. The qui-square, Fischer, t Student and Odds Ratio tests were used. Results: the results evidenced that: 1) there is an association between breast-feed and less development of oral habits $(p<0.01) ; 2)$ mothers' knowledge about breast-feed results in a prolongation of breast- feeding's period both for children with or without habits $(p<0.001)$; 3$)$ children with oral habits have a bigger relative risk to develop malocclusion at the vertical way $(p<0.001 ; O R=12.8)$, at the transversal way $(p<0.001 ; O R=4.25)$ and at the antero-posterior canines relation $(p<0.001)$. Antero-posterior alteration at deciduous second molars did not present statistical significant difference $(p=0.07)$. Conclusion: clinical results suggested that the degree of mothers' information and a prolongated breastfeed period are directly related with lower incidence of malocclusion in this phase of children's development.
\end{abstract}

Key words: Suction habits. Malocclusion. Infant feeding. 


\section{REFERÊNCIAS}

1. BAUME, L. J. Physiological tooth migration and its significance for development of occlusion. J Dent Res, Chicago, v. 29, p. 123-132, 1950.

2. BRAGHINI, M. et al. Relação entre aleitamento materno, hábito de sucção, forma do arco e profundidade do palato. Ortodontia Gaúcha, Porto Alegre, v. 5, p. 57-64, 2002.

3 CORRÊA, M. S. N. P. Hábitos bucais. In: CORREA, M. S. N. P. Odontopediatria na primeira infância. 1. ed. São Paulo: Ed. Santos. 1998. p. 561-577.

4. EKLUND, S. A. et al. Calibration for oral health epidemiological surveys. Genèv: World Health Organization, 1991. p. 16.

5. FARIA, A. R. et al. Associação entre aleitamento materno e hábitos de sucção não-nutritivos. 2000. Disponível em: <http://www.odontologia.com.br/artigos/aleitamentomaterno. htm>. Acesso em: 18 ago. 2002.

6. FERREIRA, R. I. et al. Prevalência de características da oclusão normal na dentição decídua. Pesq Odontol Bras, São Paulo, v. 15, n. 1, p. 23-28, jan./mar. 2001.

7. FERREIRA, M. I. D. T.; TOLEDO, O. A. Relação entre tempo de aleitamento materno e hábitos bucais. Rev ABO Nac, São Paulo, v. 5, p. 317-320, 1997.

8. GRABER,T. M.; VANARSDALL JÚNIOR, R. L. Diagnóstico e planejamento do tratamento ortodôntico. In:__. Ortodontia: princípios e técnicas atuais. 2. ed. Rio de Janeiro: Guanabara Koogan, 1994. p. 3-38.
9. KHOLERNE, L.; HOLST, K. Malocclusion and sucking habits of four-year-old children. Acta Paediatr Scand, Stockholm, v. 62, no. 4, p.152-159, 1976.

10. MOYERS, R. E. Etiologia da má oclusão. In: MOYERS, R. E. Ortodontia. 4. ed. Rio de Janeiro: Guanabara Koogan. 1991. p. 212-37.

11. OLIVEIRA, A. E. Uma transição epidemiológica na oclusão dental em Vitória-ES. 2001. 337 f. Dissertação (Doutorado)Faculdade de Odontologia da Universidade Federal do Rio de Janeiro, Rio de Janeiro, 2001.

12. PROFFIT, W. R. A etiologia dos problemas ortodônticos. In: PROFFIT, W. R. Ortodontia contemporânea. 3. ed. Rio de Janeiro: Guanabara Koogan, 2002. p. 105-135.

13. QUELUZ, P. D.; AIDAR, M. J. Chupeta: um hábito nocivo? JBP, v. 2, n. 8, p. $324-327,1999$

14. SERRA-NEGRA, J. M. C. et al. Estudo da associação entre aleitamento, hábitos bucais e maloclusões. Rev Odontol Univ São Paulo, São Paulo, v. 11, p. 79-86, 1997.

15. SHIMIZU, R. H. Estudo das características de dentição decídua em crianças entre 3 e 6 anos de idade. JBO, Curitiba, v. 8, p. 124-131, 2003.

16. SILVA FILHO, O. G. et al. Hábitos de sucção e má oclusão: epidemiologia na dentadura decídua. Rev Clín Ortodon Dental Press, Maringá, v. 2, n. 5, p. 57-74, 2003.

17. VENÂNCIO, S. I.; ESCUDER, M. M. L.; PEREIRA, J. C. R. A importância da informação no aleitamento natural. Estimativa de impacto da amamentação sobre a mortalidade infantil. Rev Saúde Pública, São Paulo, v. 37, n. 3, p. 319-325, jun. 2003.

18. ZUANON, A. C. C. et al. Relação entre hábito bucal e maloclusão na dentadura decídua. JBP, Curitiba, v. 3, p.104-108, 1999.

19. WORLD HEALTH ORGANIZATION, 54, 2001, Geneva. Abtracts...Geneva: World Health Assembly, 2001. (WHA54/2).
Endereço de correspondência

Daniela Feu Rosa Kroeff de Souza

Rua Moacir Avidos, n. 156, apto 804 - Praia do Canto

CEP: 29.057-230 - Vitória/ES

E-mail: danifeutz@yahoo.com.br 